\title{
THERAPEUTICAL APPROACH IN PATIENTS WITH CUTANEOUS PSEUDOLYMPHOMAS
}

\author{
Shtilionova S. ${ }^{1}$, P. Drumeva ${ }^{1}$, M. Balabanova ${ }^{3}$, I. Krasnaliev ${ }^{2}$ \\ ${ }^{1}$ Department of dermatology and venereology, Medical University - Varna \\ ${ }^{2}$ Department of pathology, Medical University - Varna \\ ${ }^{3}$ Department of dermatology and venereology, Medical University - Sofia
}

Reviewed by: assoc. prof. M. Peneva

\begin{abstract}
SUMMARY
Cutaneous pseudolymphomas are reactive lymphocytic proliferations that appear in the skin and resemble a malignant lymphoma. Most of the pseudolymphomas are caused by infections with B. Burgdorferi, others include tattoo reactions, immunizations or allergens desensibilization injections and infection with herpes simplex and zoster. The most common clinical manifestations include a single large nodule or solitary and multiple lesions. They are sharply bordered, soft, reddish, dome- shaped and covered by thinned skin. The sites of predilection include the ear lobes, nape, nipple and areola, axillae, scrotum and the dorsum of the foot.
\end{abstract}

Key words: Cutaneous Pseudolymphomas

The cutaneous pseudolymphomas present a heterogeneous group of benign reactive lymphoproliferative processes of different etiology which stimulate clinically and histologically the malignant cutaneous lymphomas. The great variety in the clinical picture of the cutaneous pseudolymphomas manifested most commonly by erythemic and infiltrating plaques, tumor lesions, papular and nodular alterations, etc., create serious differential diagnostic difficulties $(1,2,3)$.

Local medication and, in some clinical forms, general medication, too, is used for the treatment of cutaneous pseudolymphomas. The therapeutical approach is determined according to the predicted etiological factor.

A possible choice for the local treatment of the pseudolymphomas consists in the potent corticosteroid unguents such as Clobetazol propionate (Clobederm, Dermovete), Betametason dipropionate or valerate (Diprosone, Betnovate) and Flucinolon acetonid (Abricort, Flucinar).

In patients with nodular or plaque lesions accompanied with intensive itching (mainly post-scabious and post-insect pseudolymphomas) and an unsatisfactory therapeutical result from the local corticosteroid therapy, intralesion injection of corticosteroids (Flosteron, Diprophos), is administered, diluted with Lidocaine $1 \%$ in a ratio $1: 1$ - one, two or three applications altogether, in an interval 2 - 4 weeks, yielding a very good therapeutical result.

In Lime's borreliosis, doxycyclin (Vibramycin, Doxat, Dotur) is used twice daily x $100 \mathrm{mg}$ p. o. for a period of two

\footnotetext{
Address for correspondence:

S. Shtilionova, Dept. of dermatology and venereology

Medical University - Varna

e-mail: shtilionova@abv.bg
}

weeks. In case of gastrointestinal tract intolerance Amoxycilln or another antibiotic is recommended $(3,4)$.

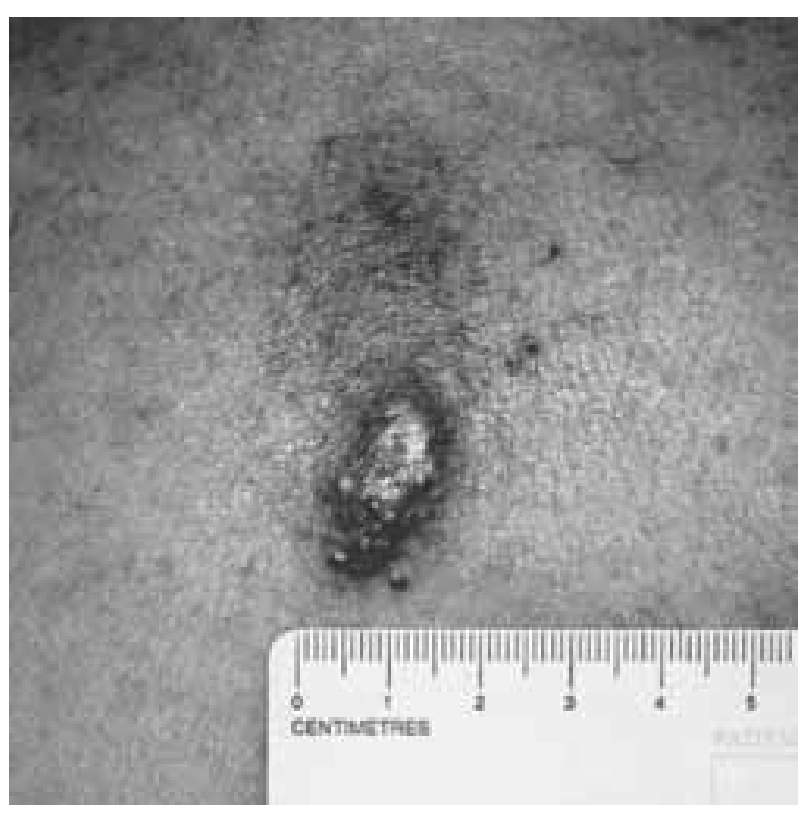

In scabies, an anti-scabies therapy is applied (based mostly on benzyl benzoate) and subsequently a local corticosteroid therapy is administered and, possibly, intralesion injection of corticosteroids.

In cutaneous pseudolymphomas resulting from insect bites, stinging by wasps, bees or others, anti-pruritic, anti-inflammatory and anti-allergic drugs are prescribed (local corticosteroids, general anti-histamine treatment) $(5,6)$. 

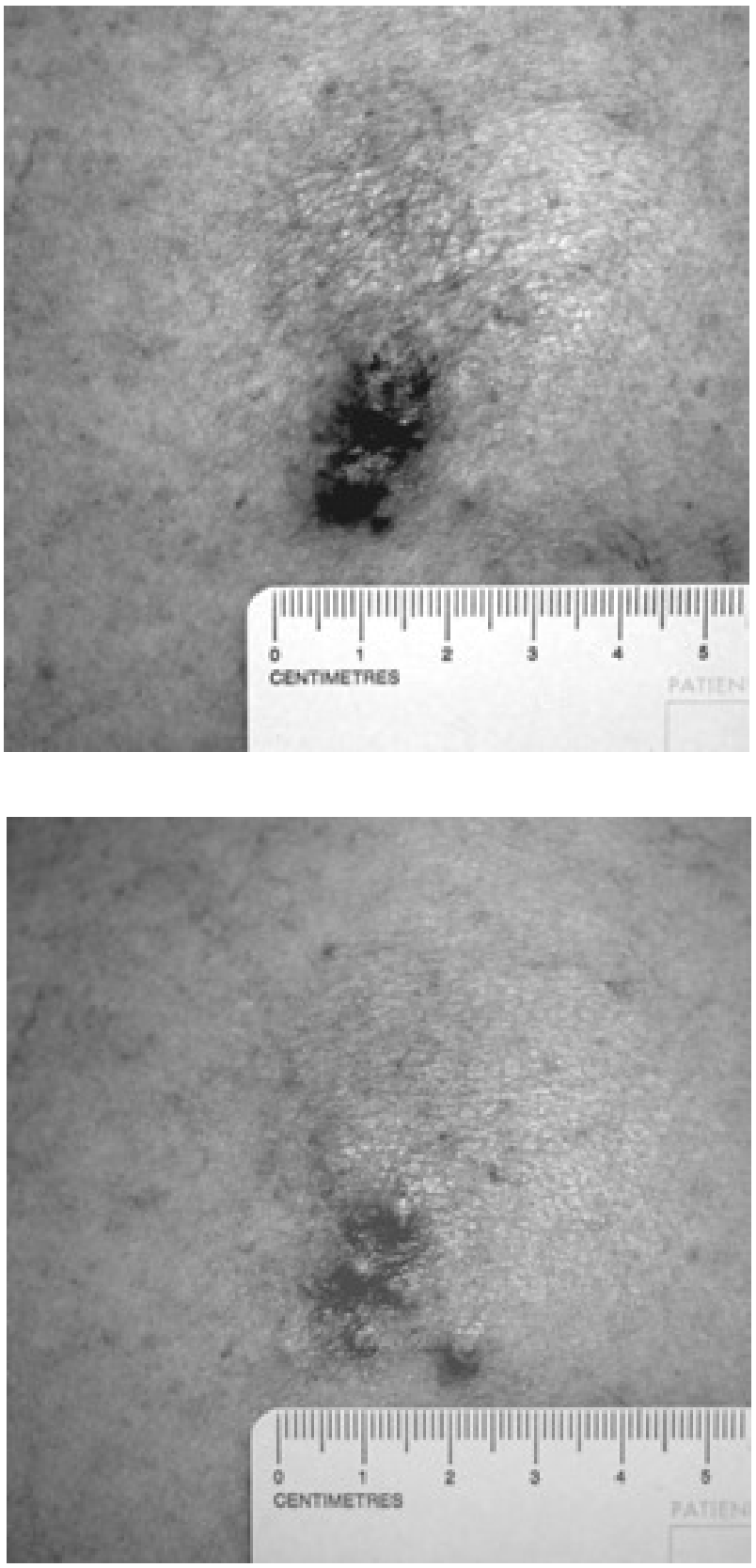

In actinic reticuloid, a possible choice of treatment is presented by local photo protection means with high SPF and corticosteroids. In general, Resochin twice daily x 1 tablet for a period of 10 days, followed by 1 tablet daily for a period of at least another 20 days. In case when there is no improvement, systemic corticosteroids are administered together with non-steroid anti-inflammatory drugs (5). The patients are instructed to avoid exposure to sunlight.

In idiopathic cutaneous pseudolymphomas, only patients with subjective complaints are treated, starting with local corticosteroids and in cases when there is no improvement, their intra-lesion application is undertaken.
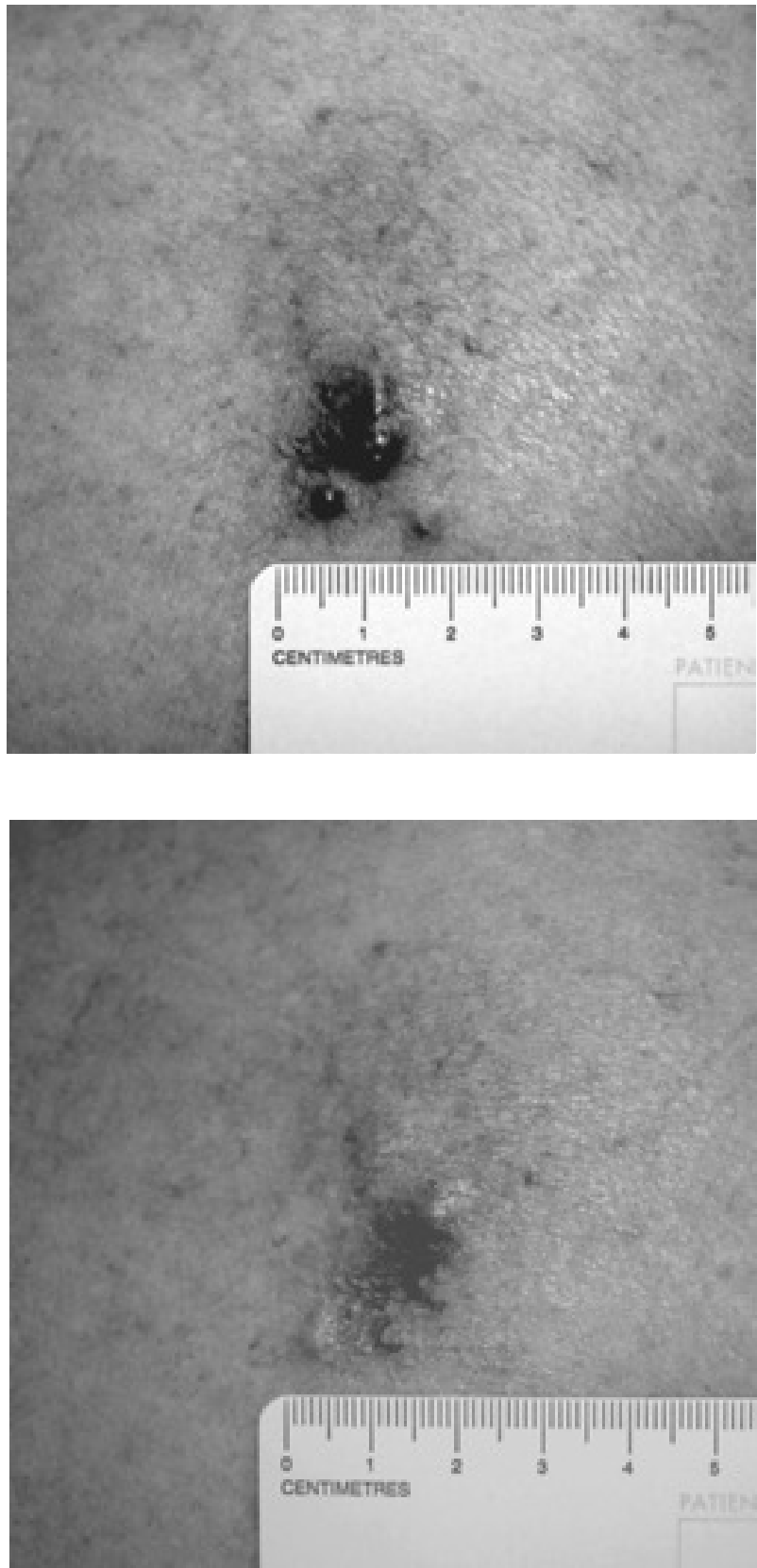

\section{DISCUSSION}

1. The choice of therapeutical approach should be made following clarification of the etiological factor.

2. In the diagnosis of cutaneous pseudolymphoma, the first drugs of choice should include the local corticosteroids and photo protectors.

3. In cases of cutaneous pseudolymphomas resistant to local corticosteroid therapy, a combination with parenteral and intra-lesion corticosteroids should be considered.

4. A parenteral antibiotic can also be included if necessary and if indicated, for a period of $1-2$ weeks according to the etiological agent.

5. Patients with cutaneous pseudolymphomas which are resistant to the applied local and parenteral therapy 
should be clinically monitored because of the risk of evolution toward malignant lymphoma.

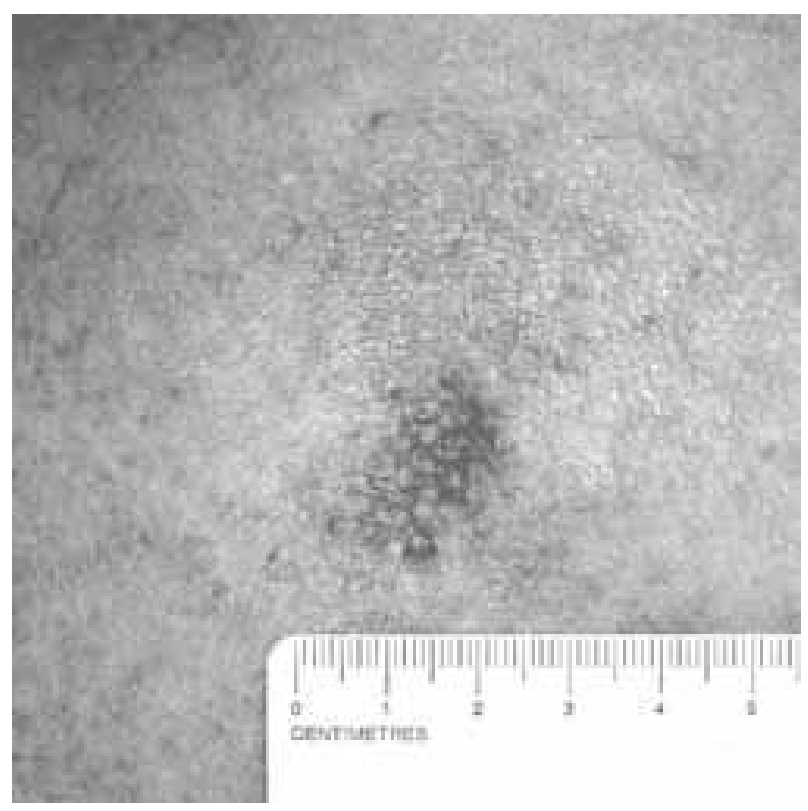

\section{BIBLIOGRAPHY}

1. Rijlaarsdam U, Scheffer E, Meijer CJLM, et al. Mycosis fungoides-like lesions associated with phenytoin and carbamazepine therapy. J Am Acad Dermatol 1991; 24: 216-222.

2. Rosenfeld S, Swiller AI, Shenoy YMV, Morrison AN. Syndrome simulating lymphosarcoma induced by diphenylhydantoin sodium. JAMA 1961; 176: 491-493.

3. Ploysangam T, Breneman DL, Mutasim DF. Cutaneous pseudolymphomas. J Am Acad Dermatol 1998; 38: 877-895; quiz 896-897.

4. Landa N, Zelickson BD, Peters MS, et al. Cutaneous lymphoma versus pseudolymphoma: gene rearrangement studies of 21 cases with clinicopathologic correlation [Abstr.]. J Invest Dermatol 1991; 96: 569A.

5. Kerl H, Ackerman AB. Inflammatory diseases that simulate lymphomas: cutaneous pseudolymphomas. In: Fitzpatrick TB, Eisen AZ, Wolff K, Freedberg IM, Austen KF (editors). Dermatology in general medicine, 4th ed. New York: McGrew-Hill, 1993, 1315-1327.

6. Haynes HA, Bernhard JD, Gange RW. Actinic reticuloid: response to combination treatment with azatioprine, hydroxychloroquine, and prednisone. $J$ Am Acad Dermatol 1984; 10: 947-952. 